\title{
A PRODUÇÃO DA DIFERENCIAÇÃO SOCIOESPACIAL EM CATANDUVA E SÃO JOSÉ DO RIO PRETO - POR MEIO DOS ESPAÇOS RESIDENCIAIS FECHADOS
}

\author{
Patrícia Helena Milani \\ Universidade Federal de Mato Grosso do Sul - UFMS \\ Professora Doutora do Curso de Geografia \\ patriciah.milani@gmail.com
}

\begin{abstract}
RESUMO
O cotidiano é nossa dimensão de análise, tendo as práticas espaciais dos sujeitos sociais pesquisados - moradores de espaços residenciais fechados de Catanduva e São José do Rio Preto - SP, enquanto plano analítico, o que nos permitiu identificar como o processo de diferenciação socioespacial se expressa na produção do espaço urbano, conferindo sentidos e significados às práticas, que envolvem relações contraditórias entre dentro e fora desses espaços de moradia. Sob o discurso da segurança, os sujeitos pesquisados, produzem estratégias de distinção socioespacial, nas quais o espaço urbano é estratégico; consideramos que os muros exercem tanto um papel de barreira material, quanto de limite simbólico, que influenciam nas práticas dos moradores e na elaboração das representações espaciais, apreendidas por meio das entrevistas, nosso principal instrumento metodológico. Ao valorizarem elementos internos desses espaços em suas narrativas, integrando um "novo estilo de vida", no qual, a segurança e o controle estão entre os aspectos representados mais positivamente, o que se produz são diferentes estratégias de diferenciação socioespacial. As maneiras como esses sujeitos vivenciam o urbano e aquilo que the é inerente são modificadas, sendo a cidade cada vez mais vivida e representada em fragmentos por esses sujeitos sociais.
\end{abstract}

Palavras-chave: Espaço urbano. Cotidiano. Práticas espaciais. Catanduva. São José do Rio Preto.

\section{LA PRODUCCIÓN DE LA DIFERENCIACIÓN SOCIOESPACIAL EN CATANDUVA Y SÃO JOSÉ DO RIO PRETO-SP POR MEDIO DE LOS ESPACIOS RESIDENCIALES CERRADOS}

\section{RESUMEN}

Lo cotidiano es nuestra dimensión de análisis, teniendo las prácticas espaciales de los sujetos sociales estudiados - habitantes de espacios residenciales cerrados de Catanduva y São José do Rio Preto-SP, mientras el plan analítico, lo que nos permitió identificar cómo el proceso de diferenciación socioespacial se expresa en la producción del espacio urbano, otorgando sentidos y significados a las prácticas que involucran las relaciones contradictorias entre dentro y fuera de estos espacios de residencia. Bajo el discurso de la seguridad, los sujetos investigados producen estrategias de distinción socioespacial, en las que el espacio urbano es estratégico; consideramos que los muros ejercen tanto un papel de barrera material como un límite simbólico, que influyen en las prácticas de los residentes y en la elaboración de las representaciones espaciales, entendidas por medio de las entrevistas, nuestro principal instrumento metodológico. Al valorar los elementos internos de estos espacios en sus narrativas, integrando un "nuevo estilo de vida", en el cual la seguridad y el control están entre los aspectos representados más positivamente, lo que se produce son diversas estrategias de la diferenciación socioespacial. Las maneras cómo estos sujetos vivencian lo urbano y aquello que les es inherente son modificadas, siendo la ciudad cada vez más vivida y representada en fragmentos por estos sujetos sociales.

Palabras clave: Espacio urbano. Cotidiano. Prácticas espaciales. Catanduva. São José do Rio Preto. 


\section{INTRODUÇÃO}

Expansão territorial por meio da implantação de novos loteamentos residenciais fechados é uma tendência que marca o processo de urbanização brasileira, desde as últimas décadas de século XX, inclusive com alteração da relação "centro-periferia", que orientou durante muito tempo a lógica de produção do espaço urbano e as práticas espaciais dos sujeitos sociais que vivem nas cidades.

Até as últimas décadas do século $X X$ a classe média e elite residiam majoritariamente no entorno do centro tradicional, em apartamentos, essa era a forma predominante de como a busca por distinção socioespacial se expressava na produção do espaço urbano, sobretudo em cidades não metropolitanas. A consolidação dos novos empreendimentos residenciais fechados não resulta no desaparecimento de outras formas de morar na cidade, como a ressaltada, mas revela uma recombinação que dão novos conteúdos a cidade e a complexifica. No processo atual, a separação espacial é radicalizada por muros e sistemas de segurança, que impedem a livre circulação dos diferentes sujeitos sociais no espaço urbano.

Elegemos os espaços residenciais fechados (murados e controlados por sistemas de segurança) de classe média por integrarem de forma significativa a produção do espaço urbano, bem como pela importância de considerarmos a classe média (principal consumidora desses espaços residenciais fechados pesquisados) como sujeitos reais que atuam na produção do espaço urbano de forma expressiva, sobretudo por meio de suas práticas espaciais cotidianas, estilos de vida e representações sociais. Esses aspectos são importantes porque uma representação moderna de mundo deve levar em conta a maneira como o sujeito vive o mundo e não somente o mundo em que ele vive. Como recorte espacial, temos duas cidades não metropolitanas Catanduva e São José do Rio Preto - SP, que por possuírem tamanhos populacionais distintos nos permitiu comparações de como o processo de diferenciação socioespacial se expressa entre duas cidades com diferentes graus de complexidades. De acordo com o último censo do IBGE (Instituto Brasileiro de Geografia e Estatística, 2010), Catanduva possui 118.853 mil habitantes e São José do Rio Preto 438.354 mil habitantes.

Compreendemos a diferenciação socioespacial como um processo espacial também em sua determinação social, o que reforça a necessidade de enfoque as práticas espaciais dos sujeitos pesquisados, para assim apreender a dimensão real da produção espacial como momento da reprodução social (CARLOS, 2007).

Os espaços residenciais fechados a que nos referimos no texto são aqueles em que adentramos para realizar entrevistas com moradores. As entrevistas foram realizadas a partir de uma rede de contatos que se intensificou no transcorrer das pesquisas de campo, conforme discutido em nossa proposta metodológica, o que também viabilizou as observações de campo, tanto dentro das residências quanto de alguns espaços coletivos. Em Catanduva, elencamos o Residencial Acapulco e, em São José do Rio Preto, os residenciais Damha IV e V, Gaivota I, Las Palmas, Quinta do Golfe, Recanto do Lago, Recanto Real e Village Damha I. Em Catanduva, frente a um universo mais restrito, pesquisamos o único espaço residencial fechado consolidado, em contraposição a São José do Rio Preto, que possui 24 espaços residenciais fechados de médio e alto padrão de consumo, o que nos possibilitou uma análise comparativa entre cidades com diferentes níveis de complexidade. Os oito empreendimentos selecionados na segunda cidade, foram aqueles que realizamos entrevistas com moradores e as observações.

A análise dessas duas realidades não metropolitanas implica no reconhecimento das particularidades que o processo de diferenciação socioespacial adquire, contudo, apesar dos recortes espaciais, levamos em conta a urbanização, suas tendências em sentido amplo, na escala brasileira, considerando as lógicas que engendram o processo.

As entrevistas semi-estruturadas e observações de campo, as últimas, feitas quando realizamos as entrevistas nas residências dos (as) moradores (as), foram nossos principais instrumentos metodológicos empreendidos para a realização da pesquisa. Por meio desses instrumentos, que embasam a metodologia qualitativa, procuramos privilegiar a fala desses sujeitos sociais (todos os nomes dos entrevistados são fictícios), seus depoimentos sobre as 
experiências vividas espaço-temporalmente, as razões que apresentaram para justificar suas escolhas relacionadas à moradia e o modo como avaliam tais experiências.

As entrevistas combinadas às observações permitiram apreender como os sujeitos elaboram representações sociais voltadas à promoção de um estilo de vida próprio desses espaços residenciais fechados, concebidos, cada vez mais, como distintivos socioespacialmente. Isso porque eles apresentaram as razões que justificam suas escolhas relacionadas ao consumo desses espaços fechados de moradia e consumo, o modo como avaliam tais experiências e os discursos que elaboram a respeito de suas próprias práticas cotidianas, os quais serão apresentados e discutidos nas seções que seguem.

\section{UMA BREVE APROXIMAÇÃO DOS ESPAÇOS RESIDENCIAIS FECHADOS PESQUISADOS}

Como ponto de partida, tomamos alguns atributos comuns a todos os espaços residenciais fechados pesquisados das duas cidades, ressaltando que, apesar de estarem presentes em todos eles, a qualidade, a valorização por parte dos moradores e o poder simbólico que esses atributos exercem na elaboração de representações variam. Tanto o Residencial Acapulco de Catanduva quanto os oito pesquisados de São José do Rio Preto possuem em comum os serviços oferecidos e equipamentos: um salão para festas (centro de convívio), duas piscinas, sendo uma para adultos e uma para as crianças, vestiários e playground; todos os espaços internos são privados, de uso comum, para os moradores e convidados. Além desses espaços, cada empreendimento, sobretudo de São José do Rio Preto possui atributos próprios, como academias, restaurantes, pista de corridas, quadras de golfes, entre outros.

Quanto ao sistema de segurança, são características presentes em todos eles: portaria com cancela abaixada 24 horas, ronda noturna, muro alto e obrigatoriedade do cadastro dos visitantes na portaria.

No que tange às regras de entrada cotidiana das empregadas domésticas, a administração de todos os residenciais confecciona um cartão que deve ser apresentado na entrada e na saída, nas portarias, diariamente. Esse documento é feito a partir de consultas prévias de dados pessoais, inclusive de antecedentes criminais. O período de permanência das empregadas, prestadores de serviços, entre outros trabalhadores, nos espaços internos dos espaços residenciais fechados é limitado entre as sete e as dezessete horas, sendo proibida a entrada dos mesmos aos sábados e domingos (inclusive nesses dias as portarias de serviços não funcionam), exceto às empregadas domésticas, que, mediante aviso à administração, são autorizadas a entrar em dias em horários extras, assim como há um caso em que a funcionária mora com os patrões, como veremos adiante.

A diferença entre as regras referentes aos visitantes é a presença, em todos os espaços residenciais fechados de São José do Rio Preto, do equipamento de entrega de tickets (instalado na portaria), inexistente no Residencial Acapulco, em Catanduva. De maneira particular, no Residencial Quinta do Golfe, há duas portarias. Na primeira, é necessária uma pré-identificação antes de passar para a segunda, onde se localiza a máquina de entrega de tickets, e mais um porteiro, além dos seguranças.

$\mathrm{Na}$ primeira entrada para a realização das entrevistas, tanto no Residencial Acapulco quanto nos residenciais de São José do Rio Preto, foi necessário, na portaria, fazer um cadastro com nome completo, RG (Registro Geral) e uma foto tirada pelo funcionário da portaria no momento da realização do cadastro. Com esse registro, as informações dos visitantes permanecem arquivadas em um banco de dados. A partir da segunda visita, faz-se a identificação na portaria e a autorização de entrada com o morador por meio de uma ligação para sua casa. Nos empreendimentos que possuem o equipamento, o ticket é impresso com os dados pessoais do visitante e deve ser devolvido na saída, o que implica maior controle sobre o acesso dos visitantes e seu tempo de permanência, pelos sistemas de segurança dos espaços residenciais fechados pesquisados de São José do Rio Preto.

\section{O ESPAÇO URBANO COMO ESTRATÉGIA DE DISTINÇÃO SOCIAL}

Embora as relações entre classes sociais não sejam o foco analítico principal do artigo, elas compõem e estruturam a realidade, portanto, se desconsiderarmos que a sociedade é dividida 
em classes sociais, tenderemos a distorcer a realidade vivida e a praticar uma violência simbólica, que encobre relações de dominação (SOUZA, 2010).

Vemos que diversos autores realizaram análises acerca de extratos econômicos, como o economista Marcelo Neri (2011), cuja metodologia utilizada foi baseada na renda domiciliar per capita, ou seja, a soma dos salários dos membros de uma família dividida pelo número de membros dessa família - a renda.

Os procedimentos metodológicos empregados para trabalhar com a problemática das classes sociais foram de cunho quantitativo e voltados para análises econômicas, uma vez que a escala de análise foi a sociedade brasileira (milhões de pessoas que cruzam os limites dos diferentes estratos econômicos), um extenso universo de estudo, necessitando, dessa forma de dados numéricos que viabilizassem as análises.

Em outra perspectiva, o sociólogo Jessé de Souza (2010) parte da crítica contundente à redução da sistematização de classe com base somente na renda, para propor um estudo com mais profundidade das realidades sociais, na tentativa de superar as análises estritamente econômicas e envolver outras dimensões analíticas nas abordagens sobre classes sociais.

Ao tratar dos valores imateriais, o autor remete-nos aos estilos de vida que os filhos da elite e de classes médias herdam, na forma de capital cultural e simbólico, o que possibilita não só a reprodução do capital material, como a permanência na mesma classe social, reproduzindo-a no tempo: as classes sociais não podem ser definidas apenas pela renda e pelo padrão de consumo, mas, antes de tudo, por um estilo de vida e uma visão de mundo prática, que se materializa no cotidiano dos sujeitos (SOUZA, 2010, p. 26). Os sujeitos pesquisados por nós compõem uma classe média, não apenas pela renda, mas por visões práticas de mundo, especialmente pela busca por distinção social, uma característica dessa classe.

As regras presentes nos espaços residenciais fechados de Catanduva e São José do Rio Preto, além das destinadas aos moradores, também se voltam ao controle dos trabalhadores que neles adentram cotidianamente para a realização de atividades tão necessárias quanto desvalorizadas (SPOSITO e GÓES, 2013, p. 251). Na perspectiva de Sposito e Góes, os equipamentos de segurança e as regras atuam no controle desses trabalhadores por serem representados cada vez mais pelos moradores entrevistados como integrantes de uma "ameaça difusa", embora essa noção vá muito além dos próprios trabalhadores.

O que se fortalece no contexto pesquisado é uma busca por diferenciação socioespacial dessa classe média e a conformação de um estilo de vida distintivo em relação à cidade, de maneira que o espaço urbano tornou-se estratégico, uma vez que a diferenciação ligada a produção espacial, nos direciona a problematizar os conteúdos dos processos constitutivos da "produção social do espaço" (LEFEBVRE, 1999), posto que tratamos de uma sociedade de classes. A diferenciação socioespacial é, ao mesmo tempo, pressuposto e produto (contraditório e necessário) do processo histórico de produção do espaço, vivida concreta e praticamente na escala do lugar, como acentua Carlos (2007, p. 46).

A busca por diferenciação socioespacial consiste em um aspecto significativo para compreender esse estilo de vida, resultante e conformador de um habitus (BOURDIEU, 2007) em consolidação no interior dos espaços residenciais fechados pesquisados, tendo a valorização e a demarcação do espaço como uma dimensão importante nesse sentido.

Identificamos o espaço como uma dimensão estratégica para consolidação desse estilo de vida distintivo. Tal dimensão é tratada de maneira intrínseca na análise, compreendendo que as intencionalidades dos sujeitos pesquisados, que consomem e valorizam os espaços residenciais fechados de Catanduva e São José do Rio Preto, estão vinculadas às formas de se distinguirem socioespacialmente, reforçando a maneira como a desigualdade social produz e se reproduz o e no espaço urbano, de forma a caracterizar e retroalimentar o processo de diferenciação socioespacial na cidade.

Esse contexto dialoga com a noção de "desenvolvimento geográfico desigual" (HARVEY, 2004) como centro explicativo das diferenciações socioespaciais; tendo a existência de uma sociedade de classes que diferencia os seus membros a partir do lugar que ocupam tanto na produção quanto na distribuição de riqueza gerada (CARLOS, 2007). 
Diante disso, nas próximas seções, tratamos dos diferentes critérios dos entrevistados de classe média e elite nas escolhas pelos espaços residenciais fechados, depoimentos que nos oferecem elementos para avançar nas discussões acerca das estratégias socioespaciais por eles empregadas na sua busca por distinção no contexto das duas cidades pesquisadas, reproduzindo a diferenciação dessa classe social a partir do lugar (e do que ele representa no âmbito da cidade) em que residem e reproduzem parte de suas vidas. Alguns entrevistados confluíram na valorização de elementos como o "espaço", no sentido de uma casa maior, com quintal e área de lazer, contraposto ao apartamento, onde residiam anteriormente; outros valorizaram de maneira mais veemente a segurança e outros combinaram esses dois elementos numa valorização concomitante do espaço e da segurança.

\title{
OUTRA ATMOSFERA QUE NÃO ERA AQUELA DA RUA
}

As opiniões e representações sociais que os sujeitos elaboram ao expressarem sobre os critérios de escolha pelo espaço residencial fechado evidenciam as primeiras estratégias de distinção socioespacial, as quais vão se explicitando ao longo da entrevista, sobretudo por fazerem de maneira constante uma contraposição entre o espaço residencial fechado e o estilo de vida distintivo que valorizam, e os diversos espaços da cidade, os quais, na maioria das vezes, desvalorizam e fazem representações negativas.

Nas respostas sobre os critérios de escolha pelo espaço residencial fechado, as quais subsidiaram as análises dessa seção, a maioria dos entrevistados fala da trajetória pregressa e dos fatores que influenciaram na opção pela mudança, evidenciando a diversidade de experiências vividas. Ainda que esse tema seja tratado logo no início das entrevistas, algumas pistas que evidenciam as estratégias de distinção já surgem e se tornam mais explícitas ao longo delas, quando as contradições também se revelam.

Ainda que não cheguemos a esses resultados exclusivamente com essas respostas iniciais, as falas que evidenciaram como critério de escolha pelo espaço residencial fechado a valorização de novos espaços de lazer, como os oferecidos pelos empreendimentos, mas, sobretudo uma casa espaçosa e a "liberdade" para os filhos (como no exemplo abaixo), expressaram uma constante produção de hierarquização espacial (MAGRINI, 2013, p. 168), baseada em critérios socioeconômicos, evidenciando uma naturalização do processo de diferenciação socioespacial presente em cidades de diferentes tamanhos populacionais.

\begin{abstract}
Na verdade, a gente nem escolheu, foi assim: morávamos em apartamento e enquanto era só eu e meu marido, estava ótimo [...], daí, quando meu filho nasceu, eu comecei a ficar mais em casa e comecei a me sentir presa e ele também [...]. E aí nós começamos a procurar terreno, só que aqui em Catanduva não tinha terreno em bairro bom. Assim, você não achava mais. Foi quando eu conheci aqui, o corretor nos trouxe, eu fiquei encantada, nós gostamos de tudo do condomínio, mas na época que nós compramos, se eu falar para você que nós estávamos pensando assim em segurança, não. [...] Mas, então, foi mais por isso mesmo, por ser um lugar legal, eu achei, e um terreno que apareceu de um tamanho bom... (Grifos nossos. Karen, professora, 40 anos, Acapulco, Catanduva)
\end{abstract}

Além de não serem naturais, as diferenças são também legados históricos-geográficos, bem como reproduzidas, sustentadas, solapadas e reconfiguradas por processos politicoseconômicos e socioecológicos que ocorrem no momento presente (HARVEY, 2004). Nesse sentido, a atenção às particularidades de cada cidade não pode ser desconsiderada quando analisamos as entrevistas, assim, a pesquisa empírica sobre Catanduva revelou a existência de terrenos à venda em bairros predominantemente habitados pela classe média alta e pela elite. Quando Karen comprou o terreno no Residencial Acapulco, em 2012, existiam terrenos à venda, por exemplo, no Bairro Agudo Romão; no entanto, o preço de um terreno estava em torno de cem mil reais, enquanto o preço pago por ela foi $50 \%$ menor do que isso, segundo relato da moradora. Karen atribui a valorização do espaço residencial fechado, dentro outros elementos, à possibilidade da instalação de um presídio em Catanduva, reforçando o binômio presídio-violência, também presente na pesquisa de Sposito e Góes (2013, p. 214). A entrevistada foi taxativa ao identificar um possível agravamento da situação da segurança, 
diretamente relacionado à instalação do presídio que, implicitamente no seu discurso, também remeteu à vinda dos familiares dos presidiários e suas facções criminosas.

Constatamos que a opção pelo residencial fechado foi baseada tanto na construção simbólica positiva de seus atributos, quanto no menor preço do terreno no período em que foi adquirido, em relação a outros bairros da cidade. A consolidação dos espaços residenciais fechados no plano simbólico está associada a uma relação que os entrevistados fazem entre o moderno e o novo e, por conseguinte, com a vida metropolitana (SPOSITO, 2004, p. 379), que reforça cada vez mais uma representação negativa da rua, enquanto espaço público e elemento basilar para a existência das cidades (MAIA, 2006, p. 170), valorizando características dos espaços internos dos empreendimentos, como o parquinho, o lago, as áreas de lazer de uso coletivo, porém privadas.

Além de Karen, nas narrativas de Letícia e Ana, a insegurança não foi mencionada como fator importante para a opção por morar em um espaço residencial fechado, como mostram os trechos abaixo. Contudo, passaram a valorizá-la depois da mudança, numa relação de "interiorização das exterioridades" (BOURDIEU, 2007), própria do habitus em constituição.

\begin{abstract}
A minha sogra mora aqui e eu vinha visitar, achei interessante, um lugar bonito e um lugar mais tranquilo para se morar. [...] A questão da segurança, que todo mundo fala, veio depois [...]. Então eu escolhi mais porque 0 ambiente era gostoso, parecia até que você estava em outra atmosfera que não era aquela da rua [...], aí depois que veio a questão da segurança, depois que você muda, que você começa achar legal poder sair a qualquer hora na rua [...]. Quando eu vim conhecer aqui, eu vi o lago, o lugar todo, parecia que você estava em um outro lugar [...], não tem aquele fluxo grande de carro, aquela coisa. De certa forma, é uma segurança, mas não aquele segurança de "estou segura por estar num lugar fechado", mas um outro tipo de segurança, de você ficar mais a vontade... (Grifo nosso. Letícia, empresário, 50 anos, Recanto Real, São José do Rio Preto)
\end{abstract}

Eu e Murilo [namorado] resolvemos nos unir e o apartamento, que era um espaço que eu gostava muito, ficou pequeno pras coisas dele. Ele já morava em uma casa, que era no Village Damha, aí eu falei "mas eu não quero, porque eu acho muito longe", aí começamos a ver casas em bairro, mas nenhuma agradou e um dia ele saiu e veio sozinho pra cá, viu essa e adorou. Eu vim, eu não sei se fui na empolgação dele, falei "ah ta bom", mas sempre com aquele pezinho atrás. Mas aquela coisa assim, eu também me vejo fora daqui, até falo para ele parece que estou passando uma temporada aqui, mas assim estou me adaptando a um lugar, é gostoso, mas nunca me vi morando num condomínio, sempre morei em casa em bairro, depois no apartamento pequeno no centro, se eu ficasse sem carro iria trabalhar a pé numa boa. Agora estamos numa adaptação. (Grifos nossos. Ana, educadora física, 49 anos, Damha V, São José do Rio Preto)

Nesse mesmo conjunto de narrativas, cujo critério de escolha não está relacionado estritamente à segurança, a fala de Ana, apesar de se contrapor aos dois depoimentos anteriores e a outros que evidenciam uma presentificação dessa forma de morar na cidade, também se combina com eles, uma vez que, apesar de não conceber essa forma de morar como a única ou a mais adequada para ela, foi a sua escolha. Isso se deve a uma combinação de fatores, como a valorização desses empreendimentos por um número cada vez maior de sujeitos sociais da classe média e uma maior oferta de imóveis de médio e alto padrão de construção, oferecida de forma contundente em espaços residenciais fechados em São José do Rio Preto, nas áreas leste e sul da cidade, como evidenciam as narrativas do casal morador no residencial Damha I:

Como que você vai comprar um terreno na zona norte? Zona norte é o seguinte, Rio Preto, zona norte é um lugar para pobre. É ao contrário da zona sul, [...] porque, quem tem dinheiro para comprar uma casa cara hoje em Rio Preto, não compra no bairro, compra a casa dentro do condomínio. (Grifos nossos. Roberto, 50 anos, construtor e Claudia, 46 anos, decoradora, Damha I, São José do Rio Preto)

Por considerando as possibilidades de diálogo entre esse conjunto de narrativas e aquelas em que os entrevistados valorizaram além da segurança, características como a maior previsibilidade e controle, sobretudo dos empregados nos espaços internos dos residenciais, o 
que também estão interligadas à segurança que almejam, na próxima seção voltaremos nossa atenção aos dois últimos.

\section{NÃO ENTRA NINGUÉM SEM INTERFONAR, NINGUÉM TE PEGA DE SURPRESA}

Em sentido mais amplo, da sociedade brasileira como um todo, é preciso levar em conta que o poder econômico pressupõe o exercício de uma dominação simbólica que lhe é concomitante (SOUZA, 2010, p. 40). Assim, os produtos simbólicos mais valorizados por essa classe média são sempre os que mais se aproximam dos consumidos pela elite e se afastam das classes populares. Algumas evidências dessa dominação simbólica se expressam em práticas espaciais mencionadas durante as entrevistas, principalmente entre os entrevistados dos espaços residenciais fechados de São José do Rio Preto.

Os depoimentos evidenciam uma satisfação pela previsibilidade dos encontros no interior dos espaços residenciais fechados, mas, sobretudo, pelos não encontros com aqueles que não têm autorização para entrar; nesse caso: pedintes e vendedores ambulantes. Verificamos que os muros e o caráter privado desses empreendimentos promovem uma despreocupação com a ordem urbana como um todo e, portanto, pautam-se num estilo de vida exclusivo e excludente (CALDEIRA, 2000, p. 309). A fala da moradora que segue é exemplar nesse sentido.

Aqui não passa vendedores, não passam nem para pedir, nem para vender. Eu acho ótimo, não entra ninguém sem interfonar, ninguém te pega de surpresa, [...] e, se você mora num bairro aberto, aí o pessoal bate, toca a campainha, e aqui não, é tudo avisado, e não tem problema nenhum. (Selma, dona de casa, 42 anos, Village Damha I, São José do Rio Preto)

Por outro lado, não desconsideramos que o cotidiano vivido produz situações que implicam a impossibilidade do fechamento em uma "totalidade sincrônica" (MASSEY, 2008, p. 168), seja pelos funcionários e prestadores de serviços que entram e saem cotidianamente desses espaços, seja pelas imprevisibilidades presentes, mesmo que de modo esporádico. De acordo com Dunker (2015, p. 54), apesar dos muros e do síndico, dentro do "condomínio" ocorrem eventos inesperados, formas imprevistas de encontro e desencontro, irrupções da vida como ela é. Conforme relataram os entrevistados de São José do Rio Preto em diferentes momentos, nem mesmo o emprego de mecanismos de controle cada vez mais sofisticados, diretamente relacionados com a incontornável necessidade de defrontar-se cotidianamente com esses trabalhadores pobres, elimina a ocorrência das imprevisibilidades. Isso faz com que outras práticas discriminatórias e de distinção sejam produzidas no âmbito dos espaços internos aos muros.

\section{[Quais são as medidas de segurança adotadas pelo condomínio?]}

É o mesmo de todos os condomínios da Encalso. Eles fazem a carteirinha hora que entra, tem a identificação com RG, CPF, eu que trabalho com obras, todo vez que a gente começa uma obra nova, a gente tem que deixar uma lista de todos os pedreiros, todo mundo que vai entrar, os antecedentes criminais deles, documentos deles e tal. Isso fica muito difícil na hora do acabamento da obra, porque aí entra muito fornecedor, marmoraria, aí nessa hora, eles [seguranças] dão uma perdidinha de controle sabe, e é onde acontece furto dentro de condomínio, principalmente em horário comercial. Então horário comercial é onde a gente tem preocupação, a gente fecha tudo e de noite a gente fica mais tranquilo. (Grifo nosso. Amanda, 27 anos, arquiteta, Damha IV, São José do Rio Preto).

A narrativa de Amanda evidencia mais uma vez uma relação direta entre pobreza e violência, essa relação, evidente no âmbito da cidade, desdobra-se nos espaços internos aos muros, especializando-se ao associar a necessidade de maior controle no horário dos trabalhadores, embora regras adicionais sejam implementadas nos casos em que os trabalhadores moram nos espaços internos aos muros, como evidenciou o entrevistado Carlos.

Ela mora com minha família [a empregada], mas não pode frequentar academia, se for empregado não pode, a piscina só como acompanhante, que eu saiba sozinhos não, sem ser morador não pode frequentar, só para os moradores. (Carlos, 49 anos, aposentado, Recanto Real, São José do Rio Preto) 
Nesse caso, ela é uma moradora, mas, antes disso, ela é empregada, então as diferenças entre as classes sociais são naturalizadas. Porém, quando questionados acerca das medidas de controle em relação aos trabalhadores, os entrevistados tendem a simplificar, anulando uma distância construída ao longo da narrativa. Produzindo uma violência simbólica, por meio de uma linguagem e um discurso baseado no encobrimento, na dissimulação e da transfiguração da real demarcação das diferenças entre esses sujeitos de diferentes classes sociais e suas posições.

Em alguns casos, são valorizadas inclusive medidas de invisibilização desses sujeitos sociais: "de forma específica, na Quinta do Golfe, os ônibus não passam lá perto, porque o condomínio é extenso, o ônibus passa só num pedaço, na parte de cima, onde está a portaria de serviço, ele não chega até a frente", como descreve Júnior, morador da Quinta do Golfe que revela, além da portaria separada em relação aos de moradores e visitantes e as estratégias de controle diário desses trabalhadores, ainda que não há pontos de ônibus na área frontal do empreendimento, acirrando medidas discriminatórias e excludentes.

Embora com diferenças em relação ao residencial Quinta do Golfe, o Residencial Recanto Real, assim como todos os empreendimentos fechados de moradia de São José do Rio Preto que pesquisamos, possui portarias separadas, destinadas exclusivamente para a entrada de moradores, visitantes e empregados. As diferenças de classe não foram tocadas, mas "resolvidas" por meio de um sutil código de circulação apartada entre os serviçais e os moradores (DUNKER, 2015, p. 50).

Quando visitamos o Residencial Recanto Real para realizar as entrevistas, não identificamos a portaria de serviço, o que somente ocorreu a partir da fala de Letícia que, de maneira naturalizada, contou-nos que a portaria destinada aos empregados se localiza do lado oposto da entrada "principal" (esta, exclusiva para moradores e visitantes) do residencial, como mostra a Figura 1. Compreendemos que os princípios de diferenciação, por serem eles o produto de tais diferenças, estão objetivamente ajustados a elas e, portanto, tendem a ser naturalizados (BOURDIEU, 2008, p. 164). Além da separação discriminatória das entradas, a distância física entre elas contribui com a separação e a invisibilização dos empregados.

Mas, por outro lado, o caso de assalto no Residencial Recanto Real, em São José do Rio Preto, narrado por Maíra e envolvendo os próprios moradores, contradiz as suspeitas que recaem sobre os trabalhadores, embora permaneçam sendo alvos das desconfianças. Nesse caso, também merece destaque o esforço da administração do empreendimento em ocultar as notícias sobre o ocorrido, sobretudo para reduzir o impacto das "habilidades imperfeitas e da falibilidade humana" (GIDDENS, 1991, p. 90), responsáveis por um espaço que tende a ser, e é valorizado por isso, cada vez mais controlado por sistemas de segurança e controle.

Figura 1 - São José do Rio Preto. Entrada principal do Residencial Recanto Real.

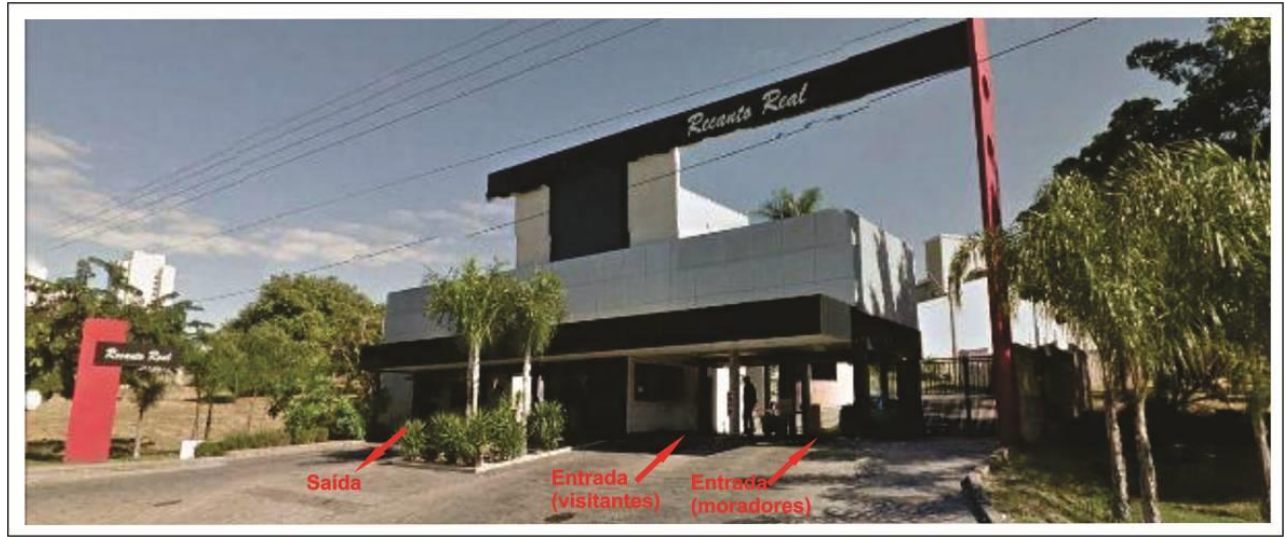

Fonte - www.diarioimoveis.com.br. Acesso em outubro de 2015. 
Quando é alguém da parte de... Alguém que vai fazer obras, ou de quem trabalha aqui, como prestadores de serviços, são todos revistados, têm que parar, abrir o porta-malas, fazer tudo certinho, porque já teve assalto aqui dentro. (Maíra, 39 anos, médica, Recanto Real, São José do Rio Preto)

\section{[E foi descoberto o responsável?]}

Envolveu o filho do dono da casa. E aqui dentro não tem câmeras, agora vai ser comprado toda essa parte das câmeras, para colocar nas ruas. Isso faz uns oito meses [o assalto], ninguém sabe como entraram, ficou estacionado em frente da casa, esperou a mulher [empregada] ir embora, entraram, pegaram o cofre e saíram, mas ficou todo mundo quieto. (Maíra, 39 anos, médica, Recanto Real, São José do Rio Preto)

[Você notou algum esforço do condomínio, para que esses casos não fossem divulgados?]

Esse assalto que teve aqui dentro, que roubaram o cofre da casa, que falam que foi o próprio filho [do dono da casa] o mandante, que eu percebo que o condomínio abafa pra ninguém falar sim, com certeza, abafam. (Maíra, 39 anos, médica, Recanto Real, São José do Rio Preto)

Por sua vez, no âmbito dos empreendimentos do Grupo Damha e do Quinta do Golfe, ficaram evidentes as medidas mais acirradas de controle e discriminação em relação aos demais residenciais fechados pesquisados; contudo, tais medidas são valorizadas por todos os moradores e tidas como modelos, como evidencia a fala abaixo apresentada de Maíra, moradora do Recanto Real. Um exemplo do sistema mais rígido de segurança são as normas de identificações dos moradores adotadas pelos empreendimentos do Grupo Damha, implementadas no Quinta do Golfe desde a inauguração, por meio de digitais, além do Tag (cartão com acionamento automático da portaria para moradores), sistema combinado para identificar o morador na entrada, quando estiver em situações consideradas de risco, por meio de uma digital específica, pré-combinada, como explica a narrativa de Olga, moradora do Damha V.

Quando a gente entra, o morador, entramos com a digital, e se tiver alguém com a gente, por exemplo, um assaltante e está entrando com a gente, aí temos uma outra digital de segurança. Temos duas digitais gravadas na portaria, uma para entrar normal e outra que eles ficam sob alerta e enviam um carro da segurança para averiguar se está tudo bem, como um código de segurança, registramos uma digital específica e quando a usamos, estamos avisando que algo está errado. É como se fosse um botão do pânico, quando vamos cadastrar as digitais, eles já pedem uma para esse tipo de aviso. (Olga, 25 anos, arquiteta, Damha V, São José do Rio Preto)

Eu ainda acho que falta um pouquinho de segurança, nessa coisa assim de não ter câmera nas ruas ainda, eu não sou a favor dos carros terem o Tag, porque tem morador que já comprou para filha que não mora aqui, pra mãe que não mora aqui, pro genro, por exemplo, minha mãe mora em Votuporanga e tem o Tag, meu marido vendeu o carro e esqueceu de tirar 0 Tag. Então eu acho que tem que ser uma digital, eu acho que tinha que ser um outro esquema [...]. Então eu vejo que falta câmera de segurança nas ruas, faltam as coisas [...], eu acho que falta acontecer alguma coisa grave para alguém tomar providência. (Maíra, 39 anos, médica, Recanto Real, São José do Rio Preto)

Além da valorização do sistema de digital para a entrada dos moradores, Maíra também ressaltou a necessidade de implantação de câmeras por todas as vias internas, uma vigilância sem intervalo de tempo, por vinte e quatro horas.

Nesse contexto de vigilância, a previsibilidade tende a predominar nas relações sociais conformadas nesse espaço, o que a própria narrativa de Célia, moradora do Residencial Acapulco de Catanduva, nos reforça, na medida em que deseja uma realidade "mais 
fortemente assistida", valorizando um olhar panóptico que tudo vê nos espaços internos aos muros, destinado a tornar possível o controle total. Os maiores investimentos em vigilância, para Célia, tendem a garantir a sensação de segurança e "intimidade" para os moradores, por outro, ocasionam uma redução e empobrecimento das experiências espaciais desses sujeitos. Além disso, a moradora valorizou em suas narrativas os espaços residenciais de São José do Rio Preto, principalmente do Grupo Damha, que exerce um papel importante no conjunto dos espaços residenciais pesquisados, como ressaltamos.

Eles vão reforçar mais essa coisa de câmera, de cerca elétrica, de ter mais uma coisa mais fortemente assistida, porque já ta meio... A gente sempre quer mais, porque, como é beira de estrada [o Residencial Acapulco], então a gente quer mais câmeras, e uma sala só pra ficar um funcionário olhando essas câmeras direto, porque por enquanto eles ficam tomando conta da frente e vendo as câmeras, agora vão ter muito mais câmeras e uma sala só monitorando. (Célia, 59 anos, aposentada, Acapulco, Catanduva)

Essa problemática da manutenção do condomínio que é muito complicado, muito complicado. Talvez, eu acho que esse condomínio não tenha tomado as rédeas bem mesmo, porque eu tenho minha sobrinha que mora no Damha em Rio Preto, eles são velhos de condomínio, então eles já têm uma outra organização. Eu acho que esse daqui ainda deixa muita coisa a desejar, porque não é uma que as pessoas... São os moradores que fazem parte dessa diretoria, então cada um tem seu emprego, seus compromissos, então fica aquela coisa meio que desajustada pro meu gosto. Eu gostaria de uma coisa mais organizada, porque não é uma coisa tão grande e acho que mereceria uma organização cem por cento eficiente, que não é. (Grifo nosso. Célia, 59 anos, aposentada, Acapulco, Catanduva)

O mais próximo desse sistema de segurança explicitado por Célia, pode ser verificado na Quinta do Golfe, porém, mesmo que haja esse acirramento da vigilância e controle, ainda não é possível identificar uma satisfação do morador.

Eu acho que a prevenção existe, sempre é possível burlar, se o cara quiser, só ele estudar um pouco ele vai conseguir, mas é lógico que a gente gostaria de mais coisas, eu acho que talvez mais rondas [...]. Eu não acho que o número de seguranças seja pouco, mas não há seguranças vinte e quatro horas em todos os lugares, porque o custo seria muito grande, mas esse tipo de coisa que resolveria. Porque câmera, a pessoa que faz o serviço de olhar as câmeras, ela não consegue ver tudo ao mesmo tempo e, mesmo que conseguir, até ela contatar alguém para chegar no local, talvez alguma coisa já aconteceu. (Grifo nosso. Júnior, 25 anos, desenvolvedor de sistemas, Quinta do Golfe, São José do Rio Preto)

Esse é um aspecto que compareceu em todas as entrevistas, entre os moradores das duas cidades, ou seja, um contínuo desejo de que os aparatos de segurança sejam reforçados. A fala de Júnior foi escolhida por ele ser morador de um dos espaços residenciais fechados que possui medidas e sistemas de segurança mais rígidos dentre os empreendimentos pesquisados, de modo semelhante aos Damhas.

Além disso, o morador explicita uma valorização dos serviços privados, nesse caso de segurança, e por outro lado uma desvalorização de um problema que é público. Esse quadro mostra uma crescente busca por soluções individuais e mercantilizadas de problemas que são coletivos. Assim se conforma uma realidade de crise, sobretudo, política, em relação à cidade, que dificulta a compreensão dos papéis e posicionamentos que os sujeitos sociais devem exercer e assumir em relação aos problemas coletivos.

O mercado propõe soluções mercantis e comerciais para tais problemas, que devem ser consumidas individualmente, assumindo um protagonismo que caberia, em primeira instância, ao poder público. Como decorrência, a segurança, que seria um direito de todos, torna-se, cada vez mais, uma mercadoria de quem pode pagar por ela. 
No plano das diferenças, nos espaços residenciais fechados de São José do Rio Preto em relação ao Residencial Acapulco, as regras dirigidas aos empregados são mais acirradas nos empreendimentos da primeira cidade. As próprias conformações arquitetônicas, que não são neutras, exaltam as posições hierárquicas e discriminatórias entre trabalhadores e moradores dos espaços residenciais de São José do Rio Preto, desde as entradas, separadas entre eles, até os controles pelos quais passam todos os dias os trabalhadores. Isso os diferencia do Residencial Acapulco, que não possui entradas separadas entre trabalhadores e moradores.

Além disso, alguns entrevistados do Residencial Acapulco mencionaram "brechas" (como no caso das falas de Karen, a seguir), o que compareceu de maneira menos significativa entre os entrevistados de São José do Rio Preto.

Por exemplo, eu tenho uma amiga, que trabalha comigo, e ela tem amigos aqui no condomínio, um dia ela estava comentando que ela tem um sonho de..., ela namora, enfim, de construir num condomínio, e ela comentou sobre a questão da segurança, você vê, ela veio com o namorado um dia à noite, veio buscar um rapaz para sair com eles, então veio com um carro bom, acho que uma Mitsubishi, um negócio assim, um carro bom, novo, não é? Aí entrou, e falaram que iriam na casa do fulano, tudo bem, a portaria anunciou, porque assim você viu na hora que você entrou, telefona e tudo bem, aí eles entraram. Na segunda vez que eles vieram, tinha trocado o porteiro, e ele estava junto com o morador, aí o morador falou assim para ele [para o amigo]: "ó vamos fazer um teste, fala boa noite para o porteiro e não fala nada onde você vai". E o cara [porteiro] liberou ele para entrar. Entendeu? Então ele passou com aquele carrão. (Karen, professora, 40 anos, Acapulco, Catanduva)

[Mas o porteiro viu o morador dentro do carro]

Não viu, porque o morador estava no banco traseiro e o carro tinha insufilme. Então, ele passou, falou boa noite, e o porteiro achou que fosse morador. Eu até comentei com o síndico, falei: olha precisa tomar mais atenção em relação a isso, só pela aparência já deixou entrar. (Grifo nosso. Karen, professora, 40 anos, Acapulco, Catanduva)

Essa diferença acentua uma particularidade de um espaço residencial fechado de uma cidade média com menores níveis de complexidades, cuja vivência cotidiana e funcionamento do sistema de segurança, apesar de ter como "modelos/referências" práticas dos espaços residenciais fechados produzidos em cidades como São José do Rio Preto e metropolitanas. No caso de Catanduva revela-se a impossibilidade de seguir esses modelos de maneira rígida, tanto pelas diferenças entre as estruturas físicas dos empreendimentos, como pelas relações sociais que predominam em cidades menores. Haja vista, que os entrevistados de Catanduva narraram algumas permanências de práticas em espaços públicos e privados fora do empreendimento fechado, como pistas de caminhadas, restaurantes e academias, o que no caso de alguns empreendimentos de São José do Rio Preto, por possuírem esses equipamentos, os moradores optam pelos espaços internos, reduzindo as vivências nos diferentes espaços da cidade.

Tais diferenças se expressam no interior dos muros dos espaços residenciais fechados de São José do Rio Preto de maneira mais evidente, em relação ao Residencial Acapulco, em Catanduva. As regras e controles sobre os trabalhadores da primeira cidade evidenciam maiores esforços em produzir e estabelecer uma hierarquia de funções e de posições, tendo como objetivo uma separação entre os iguais (moradores) e os outros - trabalhadores pobres cuja entrada pode ser cada vez mais controlada; são empregadas domésticas, pedreiros, entregadores, prestadores de serviços como eletricistas, jardineiros, etc., como ressaltamos. Vemos que a desigualdade se reforça como centro explicativo da diferenciação e está imanente à produção espacial. Tanto em seu sentido real e concreto (gerando segregações), quanto possível (a ideia de que a desigualdade vivida pode produzir a diferença como negatividade) (CARLOS, 2007). 
Para isso, além de separações físicas, são utilizados artifícios de distanciamento e controle, por meio de regras que delimitam as funções e posições como um mecanismo de cristalização das diferenças (SVAMPA, 2001) como supracitado, uma vez que a identidade social, almejada pelos entrevistados, define-se e afirma-se nessas diferenças (BOURDIEU, 2008, p. 164).

Os esforços em delimitar as posições dentro desses espaços residenciais fechados, de maneira mais intensa em São José do Rio Preto, são resultantes de relações simbólicas entre sujeitos de classes sociais diferentes. Exprimem diferenças de posição, segundo uma lógica sistemática, que conformam marcas de distinção (BOURDIEU, 2007, p. 14), as quais, ao mesmo tempo, constituem para si mesmos e para os outros, sua posição na estrutura social. Essas marcas se tornam mais evidentes nos espaços internos, o que revela os esforços e as estratégias em se conformar um estilo de vida distintivo, a partir do espaço em que vivem.

Atribuímos a diferença em relação à Catanduva à maior possibilidade dos moradores e funcionários se conhecerem nessa cidade, o que ameniza a necessidade de distinções e controles, uma vez que "cada um sabe o seu lugar e o lugar do outro", numa espécie de "contrato social", entendido como a metáfora fundadora da racionalidade social e política da modernidade ocidental (MARTINS, 2001).

Desse modo, começamos a identificar diferenças, no âmbito comparativo, com São José do Rio Preto, pela maior presença de valores que permeiam as relações sociais em uma cidade média com menores níveis de complexidade, ligados ao conhecimento entre os moradores (ainda que superficial), com o menor número de funcionários no Residencial Acapulco, tanto encarregados da segurança como da limpeza e jardinagem.

As estruturas dos espaços de uso coletivo do Residencial Acapulco são menores em comparação aos dos empreendimentos pesquisados de São José do Rio Preto e não possuem equipamentos, como academias e pistas de caminhadas internamente, os quais não necessitam de serviços especializados, portanto, de mais empregados nos espaços internos. $O$ oposto dos espaços pesquisados de São José do Rio Preto, o que exige regras destinadas a essas demarcações de posições, segundo as estratégias de distinção presentes nesses empreendimentos. Como resultado da comparação, evidencia-se uma diferença entre os espaços residenciais fechados localizados em cidades médias com diferentes tamanhos e graus de complexidades, sobretudo das relações socioespaciais.

No plano das tendências identificadas nos espaços residenciais fechados das duas cidades, os empregados reproduzem, de forma similar, na prática, os códigos de classificação de seus patrões (CALDEIRA, 2000, p. 258). A representação de quem possa ser morador ou não, tende a ser incorporada pelos funcionários, como compareceu no relato de Karen, moradora do Residencial Acapulco, de Catanduva. A importância das aparências na sociedade contemporânea, amplamente constatada por diferentes pesquisadores, é assim reafirmada.

O esforço para delimitar as posições de cada um dentro desses espaços residenciais fechados está associado ao processo de constituição de uma classe média que deseja "desfrutar" de um estilo de vida distintivo que intensifica, sobretudo, conflitos já existentes nos espaços externos aos muros, elaborando regras internas que legitimam, ao mesmo tempo em que escondem sob uma cortina de fumaça, esses conflitos que são inerentes à cidade, uma vez que: "o urbano poderia ser definido como lugar da expressão dos conflitos, invertendo a separação dos lugares onde a expressão desaparece, onde reina o silêncio, onde se estabelecem os signos da separação", nos termos de Lefebvre (1999, p. 160).

Parece que você está dentro de um outro mundinho, parece que você não participa lá de fora, é essa sensação, passou a cancela, parece que você entrou no mundo da vida real, do cotidiano, da correria, aqui fica tudo meio que num isolamento, silêncio, em outro ritmo. (Ana, educadora física, 49 anos, Damha V, São José do Rio Preto)

Eu acredito que, assim, da parte de dentro dos muros, existe uma fiscalização mais veemente, porque tem seguranças, tem câmeras, o muro para mim significa segurança, pro lado de dentro. Pro lado de fora, não sei o que acontece. Então acho que é isso, o muro significa segurança, não o muro físico em si, mas o conjunto de coisas lá dentro, porque você veja, todas as casas têm muros nas ruas, e mesmo assim minha mãe não se sentia segura, entendeu? É pelo sistema lá dentro. (Júnior, 25 anos, desenvolvedor de sistemas, Quinta do Golfe, São José do Rio Preto) 
Evidenciamos que a segurança valorizada pelos entrevistados equivale, em grande medida, às estratégias de vigilância em relação aos empregados e aqueles que acreditam que podem romper uma "ordem interna" estabelecida, regida pelas regras e sistemas de controle.

Nesse sentido, muros e sistemas de vigilância ratificam essas lógicas, porque não são apenas barreiras materiais e conjuntos técnicos, mas expressão e condição de novos valores de representações da cidade que orientam práticas espaciais, por meio da reprodução da ideia de segurança, em oposição à cidade, identificada como violenta ou perigosa (SPOSITO e GÓES, 2013, p. 301).

Porém, apesar de haver uma tendência de esses empreendimentos serem espaços homogêneos de moradia, independentemente da cidade em que são instalados, as evidencias empíricas nos revelam elementos que necessitam ser levados em conta, sobretudo porque o espaço urbano e as relações sociais já existentes não são neutros, para compreender a lógica e a dinâmica que se dá nesses espaços residenciais fechados, as quais são igualmente importantes avaliar em seus papeis na geração de padrões socioespaciais (GOTTDIENER, 2010 , p. 66), isso se verifica com algumas diferenças que verificamos entre as falas dos empreendimentos das duas cidades pesquisadas e justifica em partes o maior êxito dos empreendimentos em São José do Rio Preto.

\section{CONSIDERAÇÕES FINAIS}

Crescentemente consolidados em áreas descontínuas da cidade, os espaços residenciais fechados e controlados com sistemas de segurança atendem aos anseios dos sujeitos sociais pesquisados de fortalecer um estilo de vida cada vez mais distintivo, tanto social quanto espacialmente, em relação ao que representam como desvalorizado na cidade e que remete ao modo de vida dos segmentos populares.

A segmentação ultrapassa a forma de produção material do espaço urbano e pode ser verificada também pela dimensão simbólica do processo de diferenciação socioespacial no plano do cotidiano, viés privilegiado nesse artigo. Nossa escolha recaiu sobre o enfoque das práticas espaciais e representações sociais porque dão conteúdo à cidade e conduzem a vida urbana.

Sob o discurso da segurança, os sujeitos sociais investigados valorizam um estilo de vida distintivo socioespacialmente, consomem esses espaços de moradia, assim como os signos e os símbolos a eles associados, que acreditam se assemelhar ao modo de vida da elite e se distanciar dos segmentos populares; a partir disso, passam a conceber esses espaços fechados de moradia, cada vez mais, como a única forma de morar na cidade.

A intensificação do poder simbólico atribuído aos espaços residenciais fechados está diretamente relacionada à radicalização dos sistemas e medidas de segurança, sobretudo em relação aos empregados e prestadores de serviços que adentram cotidianamente os espaços internos aos muros. Nesse sentido, os empreendimentos do Grupo Damha e o Quinta do Golfe, em São José do Rio Preto, desempenham papel central nas falas dos entrevistados das duas cidades, quando citam elementos de valorização desses espaços de moradia. São considerados modelos, justamente por causa do rigor dos seus sistemas e medidas de segurança, que são, sobretudo, discriminatórios.

Conforme explicitamos ao longo do artigo, isso se mostrou mais intenso no contexto de São José do Rio Preto, em que o mercado imobiliário atende a maior demanda por esses produtos imobiliários, de maneira também a oferecê-los com atributos que atendam a esses anseios, ou seja, infraestruturas internas cada vez mais concebidas como exclusivas, mas que são, acima de tudo, excludentes. As regras internas e normas de convivência que marcam e hierarquizam as posições diferenciais, entre moradores e empregados, estão entre esses atributos valorizados, inclusive porque não seriam possíveis nos espaços públicos.

Apesar de algumas dessas características estarem presentes no Residencial Acapulco de Catanduva, há diferenças, a começar pelo fato de esse ser o único espaço residencial fechado consolidado da cidade. Nele há, além de uma maior valorização das relações entre os moradores, ainda que superficiais, um maior conhecimento dos empregados e prestadores de 
serviços que adentram aos espaços internos, o que ameniza a necessidade de distinções e controles tão rígidos, como encontrados nos residenciais pesquisados de São José do Rio Preto.

Diante do conjunto de reflexões, compreendemos que atualmente vivemos um período em que o processo de urbanização desafia o conceito de urbano enquanto "o lugar onde as pessoas tropeçam umas nas outras, entrelaçam-se até não mais reconhecerem os fios de suas atividades, enovelam suas situações de modo a engendrar situações imprevistas" (LEFEBVRE, 1999 , p. 46). As realidades empíricas pesquisadas não evidenciam uma negação radical ao proposto pelo autor, haja vista as práticas que permanecem nos espaços públicos e abertos, mas nos colocam novos desafios para responder aos questionamentos colocados pela complexificação do processo de produção do espaço urbano no contexto brasileiro, a partir de lógicas guiadas pela diferenciação socioespacial.

\section{AGRADECIMENTOS}

Agradecemos a Capes - Coordenação de Aperfeiçoamento de Pessoal de Nível Superior pelo apoio financeiro, fundamental para a realização da pesquisa de doutorado, a qual se vincula este artigo.

\section{REFERÊNCIAS}

BOURDIEU, Pierre. A economia das trocas simbólicas. São Paulo: Perspectiva, 2007.

. O habitus e o espaço de estilos de vida. In: A distinção: crítica social do julgamento. São Paulo: Edusp, 2008.

CALDEIRA, Teresa Pires do Rio. Cidade de muros: crime, segregação e cidadania em São Paulo. São Paulo: Edusp, 2000.

CARLOS, Ana Fani Alessandri. Diferenciação socioespacial. In: Revista Cidades, v. 4, n. 6, 2007, p. 45-60.

DUNKER, Christian Ingo Lenz. Mal-estar, sofrimento e sintonia. São Paulo: Boitempo, 2015.

GIDDENS, Antony. As consequências da modernidade. São Paulo: Universidade Estadual Paulista, 1991.

GOTTDIENER, Mark. A produção social do espaço urbano. São Paulo: Editora Universidade de São Paulo, 2010.

HARVEY, David. Espaços de esperança. São Paulo: Loyola, 2004.

IBGE - INSTITUTO BRASILEIRO DE GEOGRAFIA E ESTATíSTICA. Censo demográfico, 2010. Disponível em: <www.ibge.gov.br>. Acesso em: 08 dez. 2015.

LEFEBVRE, Henri. A revolução urbana. Trad. Sérgio Martins. Belo Horizonte: UFMG, 1999.

MAGRINI, Maria Angélica. Vida em enclaves: imaginários das cidades inseguras e fragmentação socioespacial em contextos não metropolitanos. Tese de Doutorado. Programa de Pós-Graduação em Geografia. FCT - UNESP, 2013.

MAIA, Doralice Sátyro. Lotes e ruas: componentes para análise da produção de loteamentos fechados. In: SPOSITO, Eliseu Savério; SPOSITO, Maria Encarnação Beltrão; SOBARZO, Oscar (Orgs.). Cidades médias: produção do espaço urbano e regional. São Paulo: Expressão Popular, 2006. p. 155-173.

MARTINS, José de Souza. Depoimento. In: Espaço e Debates. São Paulo: NERU, ano XVII. N. 42, p. 75-84, 2001.

MASSEY, Doreen. Pelo espaço: uma nova política da espacialidade. Rio de Janeiro: Bertrand Brasil, 2008.

NERI, Marcelo. A nova classe média: o lado brilhante da base da pirâmide. São Paulo: Saraiva, 2011. 
SOUZA, Jessé. Os batalhadores brasileiros: nova classe média ou nova classe trabalhadora? Belo Horizonte: Editora UFMG, 2010.

SPOSITO, Maria Encarnação Beltrão. 0 chão em pedaços: urbanização, economia e cidades no Estado de São Paulo. 2004. 508 p. Tese (Livre Docência) - Faculdade de Ciências e Tecnologia, Universidade Estadual Paulista, Presidente Prudente.

; GÓES, Eda Maria. Espaços fechados e cidades: insegurança urbana e fragmentação socioespacial. São Paulo: Editora Unesp, 2013.

SVAMPA, Maristella. Los que ganaron: la vida em los countries y barrios privados. Buenos Aires: Biblos, 2001.

Recebido em: 08/08/2018

Aceito para publicação em: 06/11/2018 